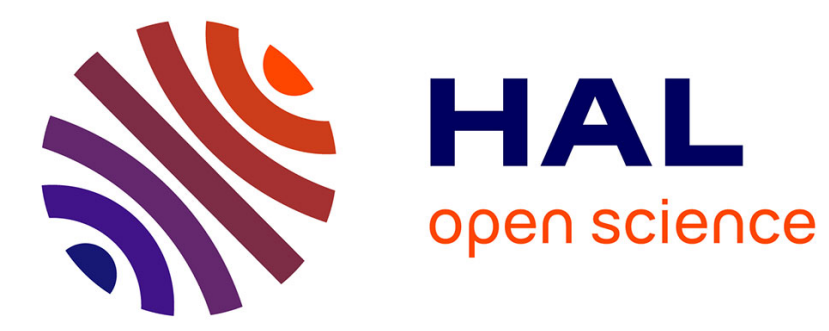

\title{
REAL-TIME DETECTION OF THE ACTIVITY OF A DOG
}

Germain Lemasson, Philippe Bruno Lucidarme, Dominique Duhaut

\section{To cite this version:}

Germain Lemasson, Philippe Bruno Lucidarme, Dominique Duhaut. REAL-TIME DETECTION OF THE ACTIVITY OF A DOG. CLAWAR 2013, Jul 2013, Sydney, Australia. pp.815-821. hal00877309

\section{HAL Id: hal-00877309 \\ https://hal.science/hal-00877309}

Submitted on 28 Oct 2013

HAL is a multi-disciplinary open access archive for the deposit and dissemination of scientific research documents, whether they are published or not. The documents may come from teaching and research institutions in France or abroad, or from public or private research centers.
L'archive ouverte pluridisciplinaire HAL, est destinée au dépôt et à la diffusion de documents scientifiques de niveau recherche, publiés ou non, émanant des établissements d'enseignement et de recherche français ou étrangers, des laboratoires publics ou privés. 


\title{
REAL-TIME DETECTION OF THE ACTIVITY OF A DOG
}

\author{
GERMAIN LEMASSON \\ UMR 6285 - Lab-STICC, Université de Bretagne Sud, France \\ PHILIPPE LUCIDARME \\ LISA - Université d'Angers, France \\ DOMINIQUE DUHAUT \\ UMR 6285 - Lab-STICC, Université de Bretagne Sud, France
}

\begin{abstract}
This paper introduces our preliminary work with assistance dogs. Even when dogs are very well trained some problems may occur in practice, typical examples are dog escaping or running after a cat. Our long term objective is to take advantage of the technology to increase the safety of the dog and its owner. Our first work focuses on the activity classification of the dog. This paper presents preliminary results for recognizing four types of activity: walk, run, lay and sit down. Experiments and results on real data collected with low-cost gyroscopes and accelerometers are presented and discussed.
\end{abstract}

\section{Introduction}

Dog is the companion of human since 14000 years [1]. The man quickly recognized his ability and gave him some task. The first working dogs were guard, hunting dogs or sheepdogs. But gradually as the human society has evolved dogs have evolved within it, leading to the creation of several breed. New tasks were given to the dogs like police dogs, urban search and rescue dogs or detection dogs. It is only relatively recently that appeared a new type of dog, the service dog. The first ones appeared after WWI for blind soldiers; it is the guide dog that we know today [2]. And more recently dogs are trained for assisting person with reduced mobility. These dogs can help people in their daily life, they can do a large number of actions such like pulling a wheelchair, bringing something, picking up or holding stuff, switching light and much more. They are also an extraordinary psychological support and there owners become more autonomous. Another type of service dog appeared in 1997, dogs for mentally disabled person like autistic children [3]. It allows the child to socialize better and prevent him from endangering himself, for example on a ballad he prevents the child from running on the road. The demand for these two types of working dog is growing. Handi'Chien a French association, has trained more than 1,000 dogs in 20 years and gets more and more demand every year [4]. 
These dogs are trained from birth, and the training lasts 2 years. The first 6 months of their life, they spend it in a foster family where they socialize and learn basic orders. Then during 18 months they are trained in specialized centers where they learn about fifty orders. At the end of their training, they are given free of charge to their new owner. The persons asking for a dog are evaluated to see if they could actually take care of the dog, they were also given a short training on how to act with their dogs. Despite these precautions, unfortunately there still are some failures, the master does not necessarily have enough the authority or the dog cannot adapt [5]. It sometimes becomes complicated; the dog passes from one master, their coach, who is dynamic and active, to a disabled person who has less mobility. It is from this observation that is born the project on which our team is currently working. The fundamental question of this project is: is it possible to increase the bond between dog and master device using robotics, mechatronics? Vernay et al. [4] discuss some scenario of interaction between a disabled person, a service dog and a robot. The first step of our project is to propose tools that might be interesting to use. We first thought of the remote detection of the dog's activity. This may be useful in two situations, when the dog is out of view during free time or if he escapes of control. Or if it keeps a mentally disabled person, combined with other tools, the dog could alert a third party if his master is endangered.

This paper describes the preliminary study we conducted and shows these results. In the first part we discuss previous works. In a second part, our work and preliminary results are presented. Before ending with a general conclusion and discussion about future works.

\section{Related works}

The use of electronic equipment on dog is quite novel; the best known is certainly the bark control collar. However at first we don't want work with negative stimuli or punishment. They are also some GPS collar that enables the owner of a dog to track it. We will certainly use GPS on our device but we chose to start with the detection of the activity of the dog. Ribeiro et al. [6] proposed a method to detect the pose of USAR dogs. It uses two 1-axis accelerometer to find the poses of USAR dogs. There method detects the transition between the poses. Results on static poses are really encouraging.

Inspired by this previous work we'll present our method which detects the static poses of the dogs but also his activity like walking and running. For this preliminary study we chose to detect only four basic activities: walking, running, laying down, sitting down.

\section{Detection of the activity}

The activities detection is the first tool of a set that we want to experiment. Some of the other tool will be GPS tracking, video streaming, and remotely giving orders. We rapidly decided to use a smartphone on the dog. It has numerous 
advantages: it is embed a small and powerful processor that already have many built-in devices, like GPS, camera, speaker, sensors, and communication capacities GSM, Bluetooth, Wi-Fi... So unlike Ribeiro et al. [6], which use two 1- axis accelerometer, we decided to take advantage of the sensor of the phone, in our case: 3 -axis accelerometer, 3 -axis gyroscope, 3 -axis magnetometer.

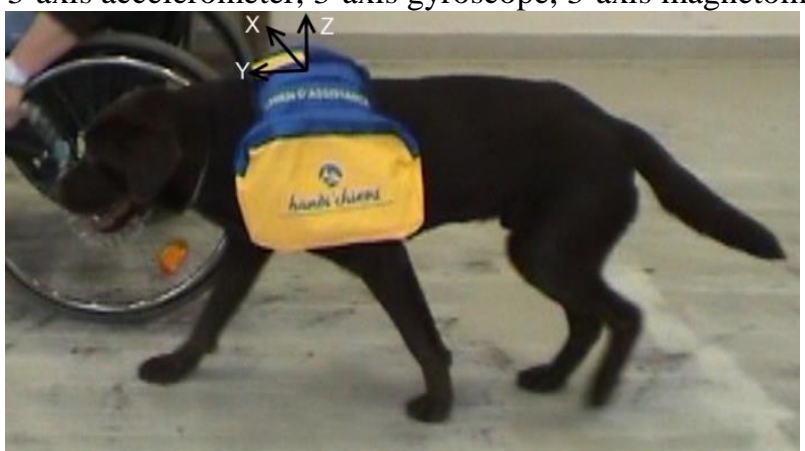

Figure 1 Dog with a smartphone on is back.

The smartphone is placed on the back of the dog. The orientation of the sensors is shown in Figure 1. Y to the dog's head, $\mathrm{X}$ to his right side and $\mathrm{Z}$ perpendicular to his back.

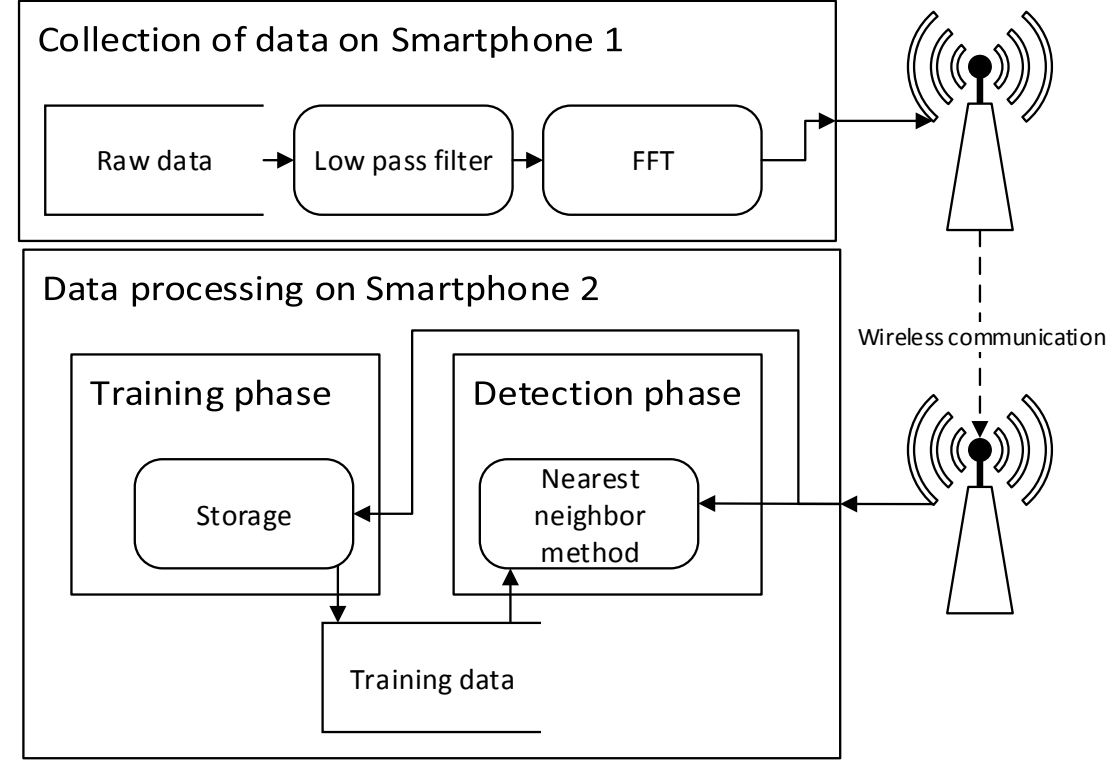

Figure 2 Data flowchart

Figure 2 describe the data flowchart of the presented method. Data are collected by the smartphone 1 on the back of the dog then sent to the smartphone 2 in the hand of the owner of the dog which performs the detection. The data collection and the data processing are explained in the following sections. 


\subsection{Collection of data.}

Among the nine available data (three axes for each of the three sensors), we chose to use only 2 of them: the accelerometer $\mathrm{z}$-axis and the gyroscope $\mathrm{z}$-axis. A first experiment on one of the dog of Handi'chien allows us to determine the significant data. We put the smartphone on the back of the dog and the trainer asks him to walk, run, sit down and lay down. After we analyzed the collected data and conclude that the accelerometer $\mathrm{z}$-axis and the gyro z-axis are sufficient to determine our four basic activities. The single z-axis accelerometer can even be sufficient but we chose to add the $\mathrm{z}$-axis gyroscope for more reliability.

Table 1 Datas collected

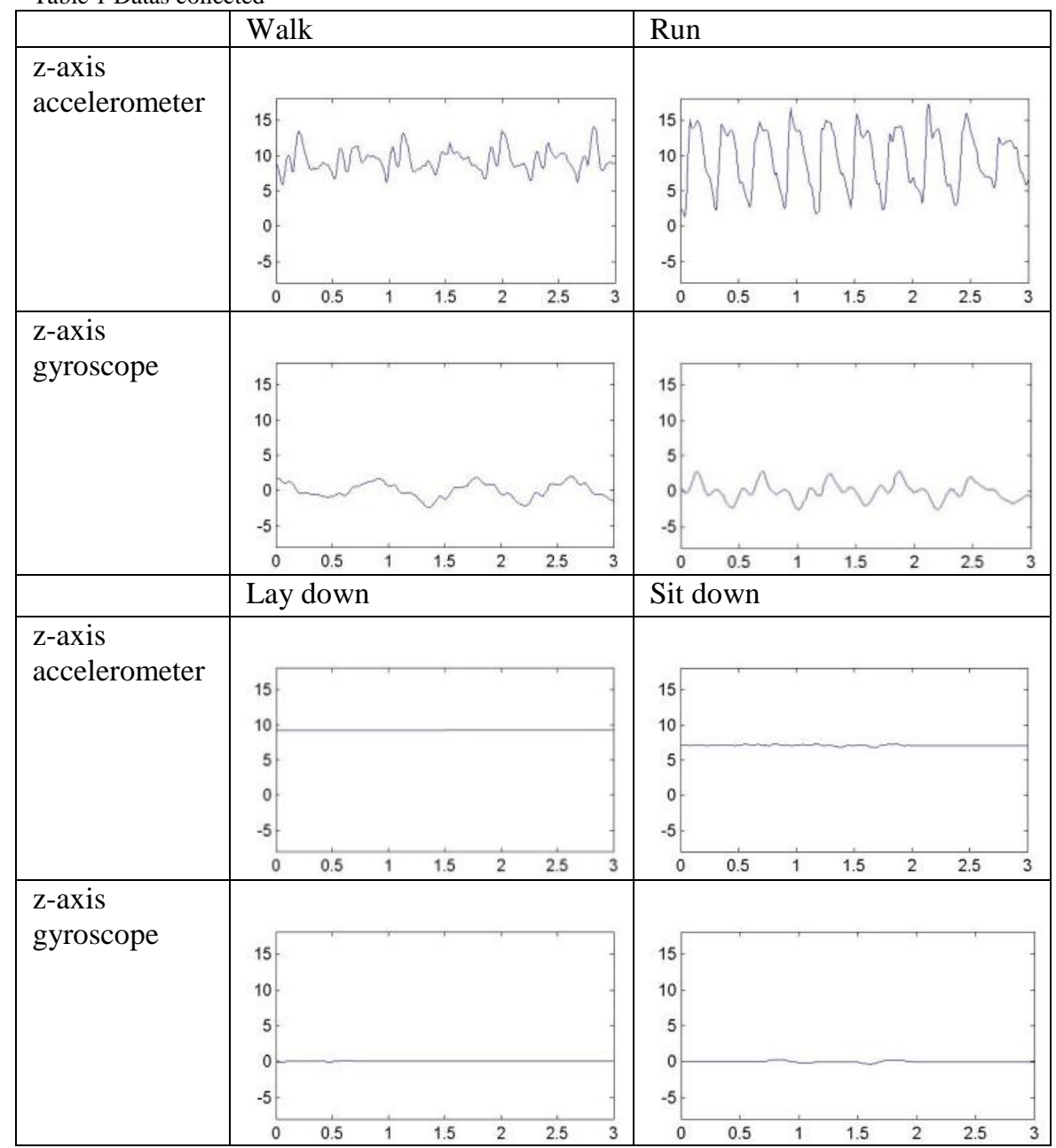


Table 1 shows the collected data. The $\mathrm{x}$-axis of the curves is the times in second ( 3 seconds) and the $y$-axis is the values returned by the $\mathrm{z}$-axis of the sensors.

We clearly see the periodicity for the walk and run. And the mean of the accelerometer z-axis is higher when the dog is lying down than when it is sitting down due to the tilt of the smartphone.

In order to extract the periodicity of the movement, data are filtered with a low pass filter and a FFT (Fast Fourier Transform) [7] is performed on the two chosen axis. Then the maximum amplitude and its corresponding frequency are extracted. This provides four values. A fifth value is calculated: the average of the accelerometer $\mathrm{z}$-axis. The window used for the processing is 2 second. It contains twice the pattern of the walk.

This processing is done locally in real time by the smartphone on the back of the dog. Every 2 seconds it sends wirelessly the fifth data to a second smartphone which perform the detection.

\subsection{Data processing}

In order to detect the activities we use the method of the nearest neighbor. It is a supervised learning method so a calibration phase is done in order to collect the training data. The owner of the dog makes him walk for 20 seconds, during this time all recovered data are stored. The operation is repeated for running, sitting position and lying position. Then we have 10 sets of data for each activity. The calibration last no more than 2-3 minutes. At the beginning of the detection phase, the calibration data are scaled and placed in a 5-dimensional space. Then each received data is scaled and we use the Minkowski distance (generalization of the Euclidean distance) to find its nearest neighbor. The activity is determined by the activity of its nearest neighbor.

After the collection of data on a second dog we saw that the curves were quite different.

Table 2 Mean frequency and mean amplitude of the run

\begin{tabular}{|l|l|l|}
\hline $\begin{array}{l}\text { Mean max frequency } \\
\text { accelerometer }\end{array}$ & 2.8035 & Dog 2 \\
\hline $\begin{array}{l}\text { Mean max amplitude } \\
\text { accelerometer }\end{array}$ & 0.4983 & 2.8754 \\
\hline $\begin{array}{l}\text { Mean max frequency } \\
\text { gyroscope }\end{array}$ & 1.5109 & 0.6654 \\
\hline $\begin{array}{l}\text { Mean max amplitude } \\
\text { gyroscope }\end{array}$ & 0.2585 & 2.4624 \\
\hline
\end{tabular}

Table 2 shows the mean value of the data collected on the two dogs for the run. We can clearly see differences on frequency on the gyroscope. It confirms the Ribeiro et al. [6] hypothesis: result are (highly) dependent on the placement of the sensor. It is difficult to place the sensor at the same position on dogs that have different size and morphology. So we chose to do the calibration phase on 
each dog. We believe it may be relevant in practice, configuring the equipment of a dog last several minute (in regard to the training that last two years).

\section{Sample results}

We tested our method for 8 minutes during which we ask the dog to walk, run, sit down and lie down. The activity changed every 30 seconds.

Table 3 Experimentation results

\begin{tabular}{|l|l|l|l|}
\hline Activity & Correct & Incorrect & \\
\hline Walk & 55 & 5 & $91 \%$ \\
\hline Race & 50 & 10 & $83 \%$ \\
\hline Sitting position & 52 & 8 & $86 \%$ \\
\hline Lying position & 45 & 15 & $75 \%$ \\
\hline
\end{tabular}

Table shows the result our experimentation. Errors in the lying position are mainly due to the position of the smartphone on the harness. Indeed, when the dog was lying but lifts high enough his head the harness and the smartphone fell slightly like if the dog was sitting down. The overall percentage of detection on our experiment is $83 \%$.

\section{Conclusion and future work}

In this paper we presented a preliminary survey on dog's activities detection. The method uses 2 smartphones with a short calibration phase. The preliminary results, based on real set of data, are quite encouraging even if it's still early for a generalization.

In our future works we will try other types of classification such as SVM [8] or Artificial Neural Network [9]. We will also consider other data of the sensors, other axis, with the aim of expanding the number of detected activities. We also plan to experiment on more dogs to see how results can be generalized. Our middle term objective is to combine it with other tools such as GPS tracking, bark detection, video streaming... any ideas are welcome!

\section{Acknowledgments}

This work is supported by French National Research Agency (ANR-012BLAN).

\section{References}

[1] A. Prestrude, "Dogs in service to humans," Comparative psychology: A handbook, pp. 386-392, 1998.

[2] E. Weiss and G. Greenberg, "Service dog selection tests: Effectiveness for dogs from animal shelters," Applied Animal Behaviour Science, vol. 53, no. 4, pp. 297-308, Jul. 1997.

[3] K. E. Burrows, C. L. Adams, and S. T. Millman, "Factors Affecting Behavior and Welfare of Service Dogs for Children With Autism Spectrum 
Disorder," Journal of Applied Animal Welfare Science, vol. 11, no. 1, pp. 42-62, 2008.

[4] D. Vernay, P. Rybarczyk, M.-C. Lebret, and Y. Rybarczyk, "Collaboration hommes, chiens et robots: quels scenarios?," 2011.

[5] R. Coppinger, L. Coppinger, and E. Skillings, "Observations on Assistance Dog Training and Use," Journal of Applied Animal Welfare Science, vol. 1, no. 2, pp. 133-144, Apr. 1998.

[6] C. Ribeiro, A. Ferworn, M. Denko, and J. Tran, "Canine Pose Estimation: A Computing for Public Safety Solution," in Canadian Conference on Computer and Robot Vision, 2009. CRV '09, 2009, pp. 37 -44.

[7] R. N. Bracewell, The Fourier transform and its applications, vol. 31999. .

[8] M. A. Hearst, S. T. Dumais, E. Osman, J. Platt, and B. Scholkopf, "Support vector machines," IEEE Intelligent Systems and their Applications, vol. 13, no. 4, pp. 18-28, 1998.

[9] K. Mehrotra, C. K. Mohan, and S. Ranka, Elements of artificial neural networks. MIT Press, 1997. 